\title{
Ultra-Processed Food Classification, their Contribution to Sodium and Added Sugar Availability, and its Relationship with Nutritional Status among Adults in Terengganu, Malaysia
}

\author{
Asma' $A^{a}$, Lokman N.A. $H^{a}$, Hayati M.Y $Y^{a}$, Zainuddin A.A $A^{b}$ \\ ${ }^{a}$ School of Food Science \& Technology, Universiti Malaysia Terengganu, 21030 Kuala Nerus, Malaysia \\ bInstitute for Public Health, 40170 Shah Alam, Selangor
}

\section{ABSTRACT}

Introduction: This cross-sectional study aims to determine the provision of foods according to NOVA classifications (an ultra-processed classification), to assess contribution of sodium and added sugar availability in each of NOVA food groups, and to evaluate nutritional status as well as to determine the relationship between sodium, added sugar availability of each NOVA foods groups and nutritional status among adults in Terengganu. Materials and methods: About 200 respondents aged between 18 and 59 years old from Kuala Nerus, Terengganu were recruited. Their dietary intake from two days of 24-hour dietary recall underwent NOVA classification and analyzed through Nutritionist Pro. All respondents had their blood pressure and fasting blood glucose taken. Spearman's rank correlation was used to evaluate the relationship between sodium and added sugar each of NOVA food groups and the nutritional status. Results: The total energy intake of the respondents was $1818 \mathrm{kcal} \pm 375.05$ per day. The energy contribution of ultra-processed group was $24 \%$. The sodium and added sugar contribution of ultra-processed group were $26 \%$ and $63 \%$, respectively. The mean blood pressure and median of blood glucose were normal at $114 / 79 \mathrm{mmHg}$ and 5.3 $\mathrm{mmol} / \mathrm{L}$, respectively. No significant correlation was found between sodium, added sugar availability of each NOVA food groups and nutritional status at $p<0.05$. Conclusion: Further studies involving vigorous research design need to be carried out in order to really understand the implication of ultra-processed food consumption towards the nutritional status of Malaysian population, as highlighted in the Malaysian Nutrition Research Priorities (2016-2020).

KEYWORDS: NOVA food classification, ultra-processed, sodium, added sugar, nutritional status, Malaysia

\section{INTRODUCTION}

The food processing industry in Malaysia has become an important part of Malaysia's economic growth. ${ }^{1}$ The availability and accessibility of these processed foods are promoted massively by the food industry, which do not necessarily guarantee nutritional quality. ${ }^{2}$ An important impact of the dramatic upsurge of the ultra-processed foods of the industries is the increased consumption of industrially ultra-processed foods. ${ }^{3}$ Ultra-processed

Corresponding author:

Dr. Asma’ Ali

School of Food Science \& Technology,

Universiti Malaysia Terengganu,

21030 Kuala Nerus, Malaysia

Tel : +609-6684969

Email : asma.ali@umt.edu.my foods (UPF) are industrially processed, highly palatable, habit forming, characteristically energy dense foods which are high in added sugar, salt and saturated fat, and often contain artificial additives, flavours and colours. ${ }^{4,5}$ The high consumption of these foods induced the food industries to increase more processed foods and has changed the current food system. ${ }^{6}$ As mass-produced food availability has increased, the consumption of ultra-processed foods increased, as well as energy intake, salt and sugar consumption. As a result, ultra-processed products not only have unfavorable nutrient profiles, but also several other unfavorable characteristics, such as inducing eating behaviors linked to noncommunicable disease (NCD) such as hypertension, type II diabetes, cardiovascular diseases in adults and children. ${ }^{7,8,9}$ 
Recently, few studies have proposed a novel approach to food classification based on the nature, degree and purpose of food processing. One of these is called NOVA classification. In NOVAs, the food is classified based on its extent and purpose of the industrial processing. ${ }^{10}$ There has been lack of studies assessing dietary intake through the nature of processing classification despite the growing number of processed foods in the Malaysian market. This study is part of the Malaysia Nutrition Research Priorities (NRP) 2016-2020 highlights and may play an important role to the government, especially the Ministry of Health, Malaysia. Therefore, this study aims to determine provision of foods according to NOVA classification, assess the contributions of sodium and added sugar availability in each of NOVA food groups, and to evaluate nutritional status (blood pressure and blood glucose) as well as the relationship between sodium and added sugar availability of each NOVA foods groups and the nutritional status of adults in Terengganu.

\section{MATERIALS AND METHODS}

\section{Sampling framework}

This was a cross-sectional study conducted in Kuala Nerus, one of the eight districts in Terengganu, using purposive sampling. Terengganu was being selected since the prevalence of diabetes and hypertension among adults aged $\geq 18$ years by states in Terengganu was $18.6 \%$ and $26.9 \%$ respectively, indicating somehow relatively high. The diabetes percentage itself is higher than the percentage of diabetes among the overall Malaysian population, $17.5 \% .^{11}$ The sample size involved in this study was calculated using Cochran's formula. Given that the prevalence of hypertension among adults aged $\geq 18$ years in Terengganu was $26.9 \%{ }^{11}$, at $95 \%$ confidence level, and desired precision of 0.07 , the minimum sample size derived was 191 . Thus, this study recruited 200 respondents aged 18 years and above. Data collection was conducted between July and September 2018. Ethical approval was approved by the University's Human Ethics Review of Universiti Malaysia Terengganu (UMT) with reference number: UMT/ JKEPM/2017/3.

\section{Research Instruments}

The questionnaires were composed of three parts: section A- Demographics profile, section B-Provision of NOVA food groups via 24-hour dietary recall, and section C-Nutritional status assessment: blood glucose level and blood pressure level. Section A was self-administered by respondents and section $B$ and $C$ is researcher- administered. For section $B$, two days of 24-hour dietary recall ( 1 weekday and 1 weekend) was used to sort out the intake of food into mutually exclusive NOVA food subgroups, and to determine the total energy intake, added sugar and sodium intake of the respondents. Each food and drinks item in a day was written down in a very detailed manner, including ingredients and preparation. All food items reported in terms of home measurements were converted to grams or milliliters using a conversion table for standardization. All data were cross checked for any inconsistencies for verification purposes.

\section{Food Classification according to Processing}

Every report of food items was classified according to the extent and purpose of food processing, following the NOVA procedures. Granting, the NOVA classification initially has four groups but due to fit the purpose of this study, the classification had been altered to three groups where we had combined Group 1 and Group 2 together. The reclassification is attributable to the main aim of this study which was to make a distinction between the ultra-processed foods and none. For that reason, these three restructured groups appeared to sufficiently portray the requirement. Thus, food items were sorted into three subgroups; (Group 1+2) unprocessed or minimally processed foods (eleven subgroups: e.g. fresh meat, roots and tubers, cereals, vegetables, legumes, fruits), processed culinary ingredients (four subgroups: e.g. plant oils, table sugar, animal fats); (Group 3) processed foods (five subgroups: e.g. unpackaged fresh bread, cheese, ham and salted meat, vegetables and fruits preserved in brine or sugar syrup); and (Group 4) ultra-processed foods (seventeen subgroups: e.g. carbonated soft drinks, sweet or savory snacks, confectionery, industrial desserts, reconstituted meat products, shelf-stable or frozen meals, industrial packaged bread).

Two days of 24-hour dietary recall were entered into several food record data composition references including Nutritionist Pro Software and MyFitnessPal smartphones app. MyFitnessPal was used to match unique food bar codes whenever possible to a product- and brand specific database containing over five million food items. No differences were 
observed when comparing MyFitnessPal nutrient values with information on the products' nutrition facts labels for a selection of commercialized food items. Additionally, Nutrient Composition of Malaysian Food, Album Makanan Malaysia, MyFCD (Malaysian Food Composition Database) and also food nutrition labelling, were used to determine total daily energy, dietary sodium and added sugar of the respondents respective to each of NOVA groups. The derived total energy daily, dietary sodium and added sugar toward of each NOVA food groups were compared to the Malaysian Recommended Nutrient Intake (RNI). Finally, section C involved nutritional assessment which involved determination of blood pressure (using OMRON blood pressure monitor) and blood glucose level (using Accu-Chek blood glucose finger-prick).

\section{Data Collection}

Prior to data collection, respondents were asked about their willingness to participate. Once agreed to participate, the respondents were given an informed consent and subject information sheet to sign. Next, respondents were interviewed for their 24 hour dietary recall and were informed for their next weekend/weekdays 24 hour dietary recall appointment. A reminder was given to all respondents a night before the nutritional assessment. They were required to fast 10 hours before the nutritional assessment. Tokens of appreciation were given to each respondent for participation.

\section{Data Analysis}

The mean (SD) was used for normal distribution data, while the medium (IQR) was used for nonnormal data. Kolmogorov-Smirnov test was used to evaluate the normality of data distribution. Spearman's rank correlation was used to evaluate the relationship between sodium and added sugar availability of the NOVA food classification and nutritional status among adults in Kuala Nerus, Terengganu. All analyses were conducted using SPSS version 21.

\section{RESULTS AND DISCUSSION}

Cleaning and Clearing the Data Quality of Daily Energy Intake
Goldberg cut-off points were used to identify and clarify the misreporting of total daily energy intake in this study. Previous studies have shown that more studies had used the Goldberg cut-off than that of the doubly labelled water method in identifying misreporting. ${ }^{12}$ Based on the Goldberg formula (reported energy intake/calculated estimate basal metabolic rate), 33 respondents were found to be under-reporting (cut-off points for under-reporting = $<0.996$ ), which was negligible for this study. Underreporting may be plausible due to recall and reporting bias, invalid data entry, wrong coding and incorrect standard amounts which could resulted in missing and implausible data. ${ }^{13}$ Therefore, the remaining 167 respondents (cut-off points for normal reporting $=0.997-2.570$ ) were further analysed specifically in this study. Generally, most of the respondents were female, Malays, married, working, had secondary education and a family income of less than RM3000 as depict in Table I.

\section{Total Energy Intake according to NOVA Classification}

After excluding all under-reporting of energy intake, the total mean energy intake of all respondents was $1818 \mathrm{kcal} \pm 375.05(\mathrm{n}=167)$. The Malaysian Adults Nutrition Survey (MANS) in 2014 found that the daily energy intake of the Malaysian population was 1466 kcal. ${ }^{14}$ while in 2003 was 1540 kcal. ${ }^{15}$ The proportion of each NOVA group to total energy intake in this study was $75 \%$ from Group 1+2 (unprocessed or minimally processed foods and processed culinary ingredients), $1 \%$ from group 3 (processed foods); and $24 \%$ from Group 4 (ultra-processed product/foods) as shown in Table II. The median energy intakes from Group 1+2, Group 3 and Group 4 were 1393.81 $\mathrm{kcal}, 8.05 \mathrm{kcal}$ and $371.77 \mathrm{kcal}$, respectively. The percentage of energy from Group $1+2$ results in the highest contribution in NOVA classification as compared to ultra-processed product/foods. Nonetheless, this is one way or another contradicted with developed countries where the combination of both Group 1 and Group 2 resulted in stagnant motion as indicated by the low percentage of contribution (approximately less than 40\%). For instance, the United State (US) daily caloric intake from 2009 to 2010 was estimated about $2060.9 \mathrm{kcal}$ with $33.1 \%$ derived from unprocessed or minimally processed (Group 1+2) which is lower compared to the contribution from Group 1 from this study. ${ }^{16}$ On the other hand, studies in Brazil and Indonesia found that 
Table I: Respondents' Socio-Demographic Profile $(n=167)$

\begin{tabular}{|c|c|c|}
\hline Socio-demoghrapic profile & Distribution & \\
\hline & n (\%) & Median (IQR) \\
\hline \multicolumn{3}{|l|}{ Gender } \\
\hline Male & $42(25.0)$ & \\
\hline Female & $125(75.0)$ & \\
\hline \multicolumn{3}{|l|}{ Age } \\
\hline $18-35$ & $125(75.0)$ & \\
\hline $36-55$ & $41(24.0)$ & $33(8.19)$ \\
\hline $56-60$ & $1(1.0)$ & \\
\hline \multicolumn{3}{|l|}{ Race } \\
\hline Malay & $153(92.0)$ & \\
\hline Chinese & $13(7.0)$ & \\
\hline Indian & $1(1.0)$ & \\
\hline \multicolumn{3}{|l|}{ Religion } \\
\hline Muslim & $154(93.0)$ & \\
\hline Buddhist & $12(6.0)$ & \\
\hline Hindu & $1(1.0)$ & \\
\hline \multicolumn{3}{|l|}{ Marital status } \\
\hline Single & $66(39)$ & \\
\hline Married & $98(59)$ & \\
\hline Divorced & $2(1)$ & \\
\hline Widow & $1(1)$ & \\
\hline \multicolumn{3}{|l|}{ Education level } \\
\hline Secondary School & $34(20.0)$ & \\
\hline Diploma & $37(22.0)$ & \\
\hline Degree & $75(45.0)$ & \\
\hline Master & $14(8.0)$ & \\
\hline $\mathrm{PhD}$ & $4(3.0)$ & \\
\hline Others & $3(2.0)$ & \\
\hline \multicolumn{3}{|l|}{ Monthly income } \\
\hline Less than RM3000 & $81(48.0)$ & \\
\hline RM3000-RM3999 & $36(22.0)$ & \\
\hline RM4000-RM4999 & $20(12.0)$ & \\
\hline RM5000-RM5999 & $16(10.0)$ & \\
\hline RM6000 and above & $14(8.0)$ & \\
\hline
\end{tabular}




\begin{tabular}{lc}
\hline Occupation & $27(16.0)$ \\
\hline Clerk & $51(30.0)$ \\
Student & $6(4.0)$ \\
Business & $8(5.0)$ \\
Science officer & $7(4.0)$ \\
Security guard & $2(1.0)$ \\
Lecturer & $41(25.0)$ \\
University staff & $4(2.0)$ \\
Technician & $21(13.0)$ \\
Others & \\
Cook everyday & $63(25.0)$ \\
Yes & $104(75.0)$ \\
No
\end{tabular}

their daily energy intake levels were $1866 \mathrm{kcal}$ and $1829 \mathrm{kcal}$ respectively, and $75.6 \%$ and $82.2 \%$ of the total energy came from unprocessed/minimally processed foods, which is quite similar to this study. ${ }^{17,18}$ It is clearly seen that this study shares similarities with the Brazilian and Indonesian studies, as higher energy consumption is coming from Group 1 as compared to the US. This finding reveals that most Malaysians have consumed more traditional cook dishes and meals (whether via home cook or acquired the traditional meal at eatery outlets) than ultra-processed foods. These results reflect those of Malaysian Adult Nutrition Survey (MANS) 2014 which depicted that white rice is the number one consumed food daily. ${ }^{19}$

Group 3 denoting processed food contributed approximately $1 \%$ of the average daily calorie intake of this sample of study, while in the $\mathrm{US}^{16}$ and Brazil ${ }^{20}$, about $9.0 \%$ comes from Group 3. The small contribution of processed food in this study probably due to that adults in Kuala Nerus, Terengganu consumed only small amounts and less frequent intake food from this group, which includes shrimp paste, anchovy sauce, fermented durian, salted fish and salted anchovies as reported in their 24-hour dietary recall. The Group 4 on NOVA classification is the ultra-processed products/foods. The percentage contribution of this Group 4 is $24 \%$ from the daily average energy intake. In Jakarta, 15.7\% of energy intake comes from ultra-processed food consumption, which is the second highest contribution in NOVA classification..$^{18}$ In contrast to this study and the one from Indonesia, most developed countries had higher contributions of Group 4 from their total energy intake. In the US, almost $60 \%$ of total energy intake consist of foods from Group 4. In France, ultra-processed food (UPF) contributes to $40 \%$ of total energy intake. ${ }^{21}$ The highest food contributors of UPF in French population were confectionery, chocolate and dairy desserts (20.0\%), biscuits and cakes $(7.8 \%)$, and pasta, and bread (70\%). In other high income countries, such as the United Kingdom, Denmark and Sweden, more than $60 \%$ of their total energy intake from highly processed foods. ${ }^{22}$ While in Mexico and Chili, both had almost $30 \%$ of daily energy intake came from Group $4 .{ }^{23}$ This shows that Terengganu adults' energy intake from ultra-processed is still not that high compared to those Western countries. ${ }^{16}$ The Brazilian and Indonesian population proved a similar proportion of calories to Terengganu for unprocessed foods and processed foods to total energy intake. ${ }^{18,24}$ Both countries had consumption of ultra-processed foods below $30 \%$ of total energy intake parallel to Malaysia. One of the plausible reasons for the similarities between these three countries is that they are experiencing industrialization and rapid economic growth on the same time line. Additionally, Brazil and Malaysia are both upper middle income countries driving towards industrialized development. ${ }^{25}$ But bear in mind that ultra-processed food consumption among this sample of this study is way higher than that of Indonesian population. It is noticeable that there are differences in ultra-processed foods consumption between low- and middle- income countries, and high income countries. 
Total Sodium and Added Sugar Contribution according to NOVA classification

The average intake of sodium $(2157.55+3291.3 \mathrm{mg})$ in this study was acceptable, as it did not go beyond the Malaysian Recommended Nutrient Intake, for which the upper limit for adults is $2300 \mathrm{mg} /$ day. The percentage of sodium contribution from group $1+2$, group 3 and group 4 were $67 \%, 7 \%$, and $26 \%$ respectively as shown in Table II. Group $1+2$ contributed the highest sodium content, which was equivalent to $1670.44(2384.8) \mathrm{mg}$. The high sodium intake from processed culinary ingredients (Group 2) was attributed to the use of salt in cooking processes preparation. This finding is similar to a study done in Indonesia which shows that sodium intake was dominantly found in the processed ingredients $(68.9 \%)$, followed by ultra-processed foods $(18.4 \%)$, unprocessed foods $(7.9 \%)$, and processed foods $(4.8 \%){ }^{18}$ These findings are in contrast with a study done in the United States, which reported that $75 \%$ of the salt intake was contributed by ultra-processed foods, then only followed by household cooking processes (15\%) and natural salts in foods $(10 \%) .{ }^{16}$ That US study was in line with a study done in Australia where the mean daily of sodium was highly contributed from UPF. ${ }^{26} \mathrm{~A}$ study from California also reported that the sodium content $(2784 \mathrm{mg} /$ day vs. $2101 \mathrm{mg} /$ day; $\mathrm{p}=.001)$ and energy from sugar $(24.9 \%$ vs. $21.4 \% ; \mathrm{p} \leq .001)$ were higher in the ultra-processed versus original menu. ${ }^{27}$ The plausible reason for this sample of study to have higher contribution of salt from Group 1 and 2 compared to salt contribution from Group 3 and 4 is because they consumed more traditional cooked foods compared to ultra-processed foods as reported in their 24-hour dietary recall. Since more than $75 \%$ of respondents (and 30\% of them were students) do not cook their meal daily, the cooked foods were normally obtained from outside premises. This might justify the higher salt contribution from non-processed foods in this study as outside cook foods would prefer to use more sodium or sodium based ingredients. Having said that, previous studies have shown that poor knowledge and practice towards reducing salt consumption can contribute towards high level of sodium in one person as well. ${ }^{28}$

The contributions of added sugar from group $1+2$, group 3 and group 4 which were 35\%, $2 \%$ and
63\% respectively towards total energy intake. Interestingly, this study shows that group 4 gained higher percentage of added sugar which is $63 \%$, equivalent to $19.5 \mathrm{~g}$. Similarly, the Chilean diet shows that almost $30 \%$ of total energy intake come from ultra-processed food, which contributed more than half of total added sugar intake. ${ }^{29}$ Most added sugar in group 4 was found to be coming from processed dairy products (flavored yogurt, condensed milk and evaporated milk). This is was in line with findings from Malaysian Adults Nutrition Survey (MANS) 2003 and MANS 2014 where sugar and sweetened condensed milk were among the top food items consumed daily in 2003 and $2014 .{ }^{19}$ Sugar is added to cordial syrup, tea, coffee, chocolate flavored beverages, and also condensed milk added to beverages, which directly comes from group 4, the ultra-processed product/foods. The high caloric of processed dairy products is because sweetened condensed milk or evaporated milk is usually added to beverages such as tea, coffee, and chocolate drinks.

\section{Relationship between Micronutrients, NOVA Classification and Nutritional Status}

Most of the respondents had normal blood pressure and blood glucose levels at $114 / 78 \mathrm{mmHg}$ and 5.3 $\mathrm{mmol} / \mathrm{L}$, respectively, as shown in Table III. Meanwhile, Table IV and Table $\mathrm{V}$ show the relationship between sodium, sugar and NOVA food groups. Evidently there is an insignificant correlation between sodium intake in each NOVA classification and blood pressure $(p>0.05)$, as well as between added sugar and blood glucose level ( $p>0.05)$. This finding is contrary to previous studies which have found strong significant relationship between high consumption of ultra-processed foods (UPF) and increased levels of blood pressure and blood glucose. ${ }^{16,30,31}$ A cohort study done among middleaged adults in Spain showed a positive correlation between UPF consumption and hypertension risk. ${ }^{31}$ This is likely caused by a higher total intake of salt, saturated fat, and sugar and an inadequate intake of fiber and micronutrients, however it warrants additional longitudinal studies to confirm the findings. Several studies have shown a positive correlation between ultra-processed food consumption and poorer diet quality in Brazil and Colombia, obesity in young and older adults in Europe, and metabolic syndrome in Lebanon..$^{20,32,33}$ However, this study has shown no significant 
Table II: Total energy, sodium and added sugar contribution according to NOVA food classification

\begin{tabular}{lll}
\hline $\begin{array}{l}\text { Total energy/ Total } \\
\text { micronutrients by NOVA groups }\end{array}$ & $\begin{array}{l}\text { Percentage of contribution towards total daily } \\
\text { energy intake (\%)/ Percentage contribution } \\
\text { towards total sodium (\%)/ Percentage } \\
\text { contribution towards total added sugar (\%) }\end{array}$ & $\begin{array}{l}\text { Mean } \pm \text { SD / } \\
\text { Median (IQR) }\end{array}$ \\
\hline $\begin{array}{l}\text { Average total energy intake } \\
\text { (kcal) }\end{array}$ & & $1818(375.05) \mathrm{kcal}$ \\
$\begin{array}{l}\text { Total energy intake for: } \\
\text { Group 1+2 }\end{array}$ & 75.0 & $1393.81 \pm 426.38 \mathrm{kcal}$ \\
Group 3 & 1.0 & $8.05(39.60) \mathrm{kcal}$ \\
Group 4 & 24.0 & $371.77(409.59) \mathrm{kcal}$ \\
Sodium (mg) & & $2157.55 \pm 3291.3$ \\
Group 1+2 & 67.0 & $1670.44(2384.8)$ \\
Group 3 & 7.0 & $154.61(198.5)$ \\
Group 4 & 26.0 & $332.50(708.0)$ \\
Sugar (g) & & $27 \pm 42.0$ \\
Group 1+2 & 35.0 & $7.50(12.0)$ \\
Group 3 & 2.0 & $0(0.0)$ \\
Group 4 & 63.0 & $19.50(30.0)$ \\
\hline
\end{tabular}

relationships between ultra-processed foods, blood pressure and blood glucose levels possibly due to low consumption of ultra-processed foods, which may conceivably have no influence on blood pressure and blood glucose. An additional conceivable revelation for the mentioned end result is due to the assortment of respondents that comprise of different age groups which shall demonstrate different metabolic rates and therefore different energy expenditure. ${ }^{34}$ The nonsignificant correlation between UPF and blood pressure and blood glucose could be attributed to the research subjects; which mainly represented by those in the youngest category in terms of age, as a result it will somehow have higher metabolic rates compared to greater age category.

Table III: Nutritional assessment on blood pressure and blood glucose

\begin{tabular}{|c|c|c|}
\hline \multicolumn{3}{|c|}{ Distribution } \\
\hline Nutritional Status & n (\%) & $\begin{array}{c}\text { Mean } \pm \text { SD / } \\
\text { Median (IQR) }\end{array}$ \\
\hline \multicolumn{3}{|l|}{ Blood Pressure (mmHg) } \\
\hline Systolic & & $114 \pm 15.19$ \\
\hline Normal & $114(68.3)$ & \\
\hline Elevated & $25(15.0)$ & \\
\hline Hypertension Stage 1 & $18(10.8)$ & \\
\hline Hypertension Stage 2 & $10(6.0)$ & \\
\hline Diastolic & & $78 \pm 11.49$ \\
\hline Normal & $98(58.7)$ & \\
\hline Elevated & $39(23.4)$ & \\
\hline Hypertension Stage 1 & $25(15.0)$ & \\
\hline Hypertension Stage 2 & $4(2.4)$ & \\
\hline Hypertensive Crisis & $10.6)$ & \\
\hline Blood Glucose (mmol/L) & & $5.3(0.80)$ \\
\hline Normal & $115(68.9)$ & \\
\hline Pre diabetes & $47(28.1)$ & \\
\hline Diabetes & $5(3.0)$ & \\
\hline
\end{tabular}


Table IV: Relationship between sodium in each NOVA classification and level of blood pressure

\begin{tabular}{|c|c|c|c|c|}
\hline \multirow{3}{*}{$\begin{array}{c}\text { Sodium } \\
\text { Contribution }\end{array}$} & \multicolumn{4}{|c|}{ Blood Pressure } \\
\hline & \multicolumn{2}{|c|}{ Systolic } & \multicolumn{2}{|c|}{ Diastolic } \\
\hline & r value & p-value & r value & p-value \\
\hline Group $1+2$ & $0.123^{b}$ & 0.114 & $0.007^{\mathrm{b}}$ & 0.930 \\
\hline Group 3 & $-0.048^{b}$ & 0.539 & $-0.005^{b}$ & 0.945 \\
\hline Group 4 & $0.096^{\mathrm{b}}$ & 0.217 & $0.081^{\mathrm{b}}$ & 0.297 \\
\hline \multicolumn{5}{|c|}{$\begin{array}{l}\text { earson correlation test is used as the data is normal } \\
\text { pearman's rank correlation test is used as the data is not normal } \\
\text { ignificantly difference at } p \text {-value }(<0.05)\end{array}$} \\
\hline \multirow{2}{*}{\multicolumn{2}{|c|}{ Added Sugar Contribution }} & \multicolumn{3}{|c|}{ Blood Glucose } \\
\hline & & r value & \multicolumn{2}{|r|}{$p$-value } \\
\hline \multicolumn{2}{|c|}{ Group $1+2$} & $0.04^{\mathrm{b}}$ & \multicolumn{2}{|r|}{0.957} \\
\hline \multicolumn{2}{|c|}{ Group 3} & $-0.03^{b}$ & \multicolumn{2}{|r|}{0.702} \\
\hline \multicolumn{2}{|c|}{ Group 4} & $-0.00^{b}$ & & 0.995 \\
\hline
\end{tabular}

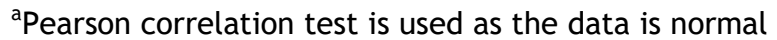

'Spearman's rank correlation test is used as the data is not normal

"Significantly difference at p-value $(<0.05)$
}

\section{CONCLUSION}

This study has shown that the energy contributions of ultra-processed group were $24 \%$. The values for sodium and added sugar contribution of ultraprocessed group were $26 \%$ and $63 \%$ respectively. The results of this investigation show that there were no significant correlations between sodium, added sugar availability of each NOVA food groups and nutritional status among adults in Kuala Nerus, Terengganu. However, this study has provided a deeper insight into classifying foods according to the nature of processing, compared to traditional methods of classification. To our knowledge, this study has been one of the first attempts to thoroughly examine provision of foods according to NOVA classification in Malaysia.

With regard to this NOVA approach, some limitations need to be acknowledged. First, respondents may report their food consumption inaccurately for the various reasons related. The Malaysia Nutrient Food Composition Book and Nutritionist Pro software have not been recently updated and this may affect the accuracy in determining the total energy, sodium as well as sugar intake. Some nutrients profiling of sodium and sugar content on food labelling were missing. There are various standard recipes for Malaysian cooked meals and therefore concerns arise in disaggregating those cooked meals along with their nutrient contribution according to the NOVA approach. In regard to variance of standard recipe, we also addressed some issues in estimating the portion size used for the preparation of the cooked dishes. This study has spurred many questions which call for further investigation. Further study is needed to fully understand the implications of high consumption of ultra-processed food on the sodium and added sugar availability of the Malaysian population and how this would affect the blood pressure and blood glucose of an individual by controlling for confounding variables (i.e. age, gender, etc). Although the findings should be interpreted with caution, this study has attempted to fill the research gap, as few studies have been done in Malaysia on ultra-processed foods and their links to sodium and added sugar availability.

\section{CONFLICT OF INTEREST}

The authors confirm that there are no known conflicts of interest associated with this publication.

\section{ACKNOWLEDGMENTS}

The authors would like to express their sincere gratitude to all respondents for their participation, full cooperation and patience during the study. This study was funded under the Universiti Malaysia Terengganu (UMT)'s Tabung Penyelidik Muda scheme (No. Vot: 68007/2016/83). 


\section{REFERENCES}

1. Popkin BM, Gordon-Larsen P. The nutrition transition: worldwide obesity dynamics and their determinants. International Journal of Obesity 2004; 28: 2.

2. Popkin BM, Adair LS, Ng SW. Global nutrition transition and the pandemic of obesity in developing countries. Nutrition Reviews 2012; 70: 3-21.

3. Monteiro CA, Cannon G, Levy R. NOVA. The star shines bright. World Nutrition 2016; 7: 2838.

4. Louzada, MLC, Baraldi LG, Steele EM, Martins APB, Canella DS, Moubarac JC, Monteiro CA. Consumption of ultra-processed foods and obesity in Barzillian adolescent and adults. Preventive Medicine 2015; 7: 18.

5. Popkin BM. The nutrition transition is speeding up: a global perspective. In Nutritional Health. Strategies for Disease Prevention 2012; 3: 85-99.

6. World Health Organization. Diet, nutrition, and the prevention of chronic diseases: Report of joint WHO/FAO expert consultation. Geneva: World Health Organization 2003; 149 p.

7. O'Halloran SA, Lacy KE, Woods J, Grimes CA, Campbell KJ, Nowson CA. The provision of ultra-processed foods and their contribution to sodium availability in Australian long day care centres. Public Health Nutrition 2017; 21: 134-141.

8. Tavares LF, Fonseca SC, Garcia Rosa ML. Relationship between ultra-processed foods and metabolic syndrome in adolescents from a Brazilian Family Doctor Program. Public health nutrition 2011; 15: 82.

9. Department of Statistics, Malaysia. Report on Household Expenditure Survey Malaysia 2009/10. Terengganu, Malaysia: Department of Statistics; 2011.

10. Fardet A, Rock E, Bassama J, Bohuon P, Prabhasankar P, Monteiro C, Achir N. Current Food Classifications in Epidemiological Studies Do Not Enable Solid Nutritional Recommendations for Preventing Diet-Related Chronic Diseases: The Impact of Food Processing. Advances in Nutrition 2015; 6: 629 $-638$.

11. Institute for Public Health. 2015 National and Morbidity Survey 2015. Retrieved from
https://www.iku.gov.my/images/IKU/ Document/REPORT/nhmsreport2015vo.pdf. Accessed March 10, 2017.

12. Poslusna K, Ruprich J, Vries JH, Jakubikova M, Veer PV. Misreporting of energy and micronutrient intake estimated by food records and 24-hour recalls, control and adjustment methods in practice. British Journal of Nutrition 2009; 101: 2.

13. Hebestreit A, Börnhorst C, Barba G, Siani A, Huybrechts I, Tognon G, Krogh V. Erratum to: Associations between energy intake, daily food intake and energy density of foods and BMI Zscore in 2-9-year-old European children. European Journal of Nutrition 2014; 53: 1297 1298.

14. Zainuddin AA, Rusidah S, Hasnan A, Chong, Zalilah MS, Wan AMAB. Household food insecurity in Malaysia: findings from Malaysian Adults Nutrition Survey. The Medical Journal of Malaysia 2015; 70: 1

15. Norimah AK, Safiah M, Jamal K, Haslinda S, Zuhaida H, Rohida S, Fatimah S, Norazlin S, Poh BK, Kandiah M, Zalilah S, Manan WMW, Fatimah S, Azmi MY. Food Consumption Patterns: Findings from the Malaysian Adult Nutrition Survey (MANS). Malaysian Journal of Nutrition 2008; 14: 25-39.

16. Steele EM, Popkin BM, Swinburn B, Monteiro CA. The share of ultra-processed foods and the overall nutritional quality of diets in the US: Evidence from a nationally representative cross -sectional study. Population Health Metrics 2017; 15: 1.

17. Louzada MLC, Baraldi LG, Steele EM, Martins APB, Canella DS, Moubarac JC, Monteiro CA. Consumption of ultra-processed foods and obesity in Barzillian adolescent and adults. Preventive Medicine 2015; 7: 18.

18. Setyowati D, Andarwulan N, Giriwono EP. Processed and ultra-processed food consumption pattern in the Jakarta Individual Food Consumption Survey 2014. Asia Pacific Journal Clinic Nutrition 2018; 27: 840-847.

19. Kasim NM, Ahmad MH, Baharudin A, Naidu BM, Ying $C Y$, Aris T. Food choices among Malaysian adults: Findings from Malaysian Adults Nutrition Survey (MANS) 2003 and MANS 2014. Nutritional Status, Dietary Intake and Body Composition. Malaysian Journal of Nutrition 2018; 24(1):63 75.

20. Louzada ML, Ricardo CZ, Steele EM, Levy RB, 
Cannon G, Monteiro CA. The share of ultraprocessed foods determines the overall nutritional quality of diets in Brazil. Public Health Nutrition 2017; 21: 94-102.

21. Julia $C$, Martinez L, Allès $B$, Touvier $M$, Hercberg S, Méjean C, Kesse-Guyot E. Contribution of ultra-processed foods in the diet of adults from the French Nutri Net-Santé study. Public Health Nutrition 2017; 21: 27-37.

22. Slimani N, Deharveng $G$, Southgate DA, Biessy C, Chajes V, van Bakel MM, Boutron-Ruault MC, McTaggart A, Grioni S, Verkaik-Kloosterman J, Huybrechts I, Amiano P, Jenab M, Vignat J, Bouckaert K, Casagrande C, Ferrari $P$, Zourna $P$, Trichopoulou A, Wirfalt E, Johansson $G$, Rohrmann S, Illner AK, Barricarte A, Rodriguez L, Touvier M, Niravong M, Mulligan A, Crowe $F$, Ocke MC, van der Schouw YT, Bendinelli B, Lauria C, Brustad M, Hjartaker A, Tjonneland $A$, Jensen AM, Riboli E, Bingham S. Contribution of highly industrially processed foods to the nutrient intakes and patterns of middle-aged populations in the European Prospective Investigation into Cancer and Nutrition study. European Journal Clinic Nutrition 2009; 63: 206-25.

23. Kelly B, Jacoby E. Public Health Nutrition special issue on ultra-processed foods. Public Health Nutrition 2018; 21: 1-4.

24. Monteiro CA. The big issue is ultra-processing. World Nutrition 2010; 1: 237-269.

25. Schatzl L, Wessel K, Lee YW. 1997. 'Newly Industrialized Countries.' (Institute of Southeast Asian Studies: Singapore).

26. O'Halloran SA, Lacy KE, Woods J, Grimes CA, Campbell KJ, Nowson CA. The provision of ultra-processed foods and their contribution to sodium availability in Australian long day care centres. Public Health Nutrition 2017; 21: 134141.

27. Tseng M, Neill DB, Teaford SF, Nazmi A. Alternative MyPlate Menus: Effects of UltraProcessed Foods on Saturated Fat, Sugar, and Sodium Content. Journal of Nutrition Education and Behavior 2018; 50.

28. Mahat DI, Tamil MZ, Azmi M, Mahmood IM, Othman F, Ambak R. The Association of Knowledge, Attitude and Practice with 24 Hours Urinary Sodium Excretion among Malay Healthcare Staff in Malaysia. International Journal of Public Health Research 2017; 7.
29. Cediel G, Reyes M, Louzada ML, Steele EM, Monteiro CA, Corvalán C, Uauy R. Ultraprocessed foods and added sugars in the Chilean diet 2010. Public Health Nutrition 2017; 21: 125-133.

30. Moubarac JC, Martins AP, Claro R. Consumption of ultra-processed foods and likely impact on human health. Evidence from Canada. Public Health Nutrition 2012; 16: 2240-224.

31. Mendonça RD, Lopes AC, Pimenta AM, Gea A, Martinez-Gonzalez MA, Bes-Rastrollo M. UltraProcessed Food Consumption and the Incidence of Hypertension in a Mediterranean Cohort: The Seguimiento Universidad de Navarra Project. American Journal of Hypertension 2017.

32. Monteiro CA, Moubarac J, Levy RB, Canella DS, Louzada ML, Cannon G. Household availability of ultra-processed foods and obesity in nineteen European countries. Public Health Nutrition 2017; 21: 18-26.

33. Cornwell B, Villamor E, Mora-Plazas M, Marin C, Monteiro CA, Baylin A. Processed and ultraprocessed foods are associated with lowerquality nutrient profiles in children from Colombia. Public Health Nutrition 2017; 21: 254.

34. Ismail MN, Ng KK, Chee SS, Roslee R, Zawiah H. Predictive equations for the estimation of basal metabolic rate in Malaysian adults. Malaysian Journal of Nutrition. 1998; 4(1\&2):81-90. 